\title{
In Vitro Bioactivity of PMMA-co-EHA Composites Filled with $\mathrm{SiO}_{2}$-Free Glass
}

\author{
P. P. Lopes, ${ }^{*}$ B. J. M. Leite Ferreira, ${ }^{*}$ R. N. Correia, ${ }^{*}$ and H. F. V. Fernandes ${ }^{*}$ \\ * Department of Ceramics and Glass Engineering, CICECO, University of Aveiro, Campus de \\ Santiago, 3810-193, Portugal.
}

Bioactive materials for potential medical application have inspired and stimulated new searches. It has been confirmed that bioactive glasses bond to living bone through an apatite layer that precipitates on their surface in physiological media. These glasses normally constituted by silica, where the silicon is the network former, induce apatite nucleation by the formation of Si-OH groups [1]. The presence of $\mathrm{OH}$ groups seems to be of utmost importance in the bioactive behaviour of materials. It was revealed that even metals, such as pure titania gel can bond to bone, if previously subjected to alkali and heat treatments [2]. In the present work a new composite with a Ca-P-Ti glass was synthesized and its in vitro bioactivity was studied in Kokubo's simulated body fluid. It is believed that the formation of Ti-OH groups on the glass can induce apatite precipitation on the composites surface.

The prepared composites consist of a poly(methylmethacrylate)-co-(ethylhexylacrylate) (PMMAco-EHA) matrix filled with a glass with composition $14 \% \mathrm{TiO}_{2}-43 \% \mathrm{P}_{2} \mathrm{O}_{5}-43 \% \mathrm{CaO}(\mathrm{mol} \%)$. The filler particle mean size was approximately $10 \mu \mathrm{m}$. Samples were soaked in Simulated Body Fluid (SBF), whose ionic composition approximates that of human blood plasma, maintained at $37^{\circ} \mathrm{C}$ for $0,1,3,7,14$ and 21 days. The in vitro bioactivity of the composites was assessed by X-ray diffraction (XRD) and scanning electron microscopy coupled with X-ray energy dispersive spectroscopy (SEM-EDS).

The present data provide initial characterization of the composite filled with a silica-free glass, as prepared and after immersion in synthetic plasma. Micrographs of the composite surfaces, after soaking in SBF are shown in Fig. 1. It is clear that after soaking for 3 days spherical precipitates developed on the composite surface. The EDS analysis reported that the titanium content decreased and the composition of the precipitates is rich in $\mathrm{Ca}$ and $\mathrm{P}$ (Fig.2). The average $\mathrm{Ca} / \mathrm{P}$ atomic ratio in this surface layer is around 1,06 . For natural bone apatite the value usually reported for $\mathrm{Ca} / \mathrm{P}$ atomic ratio is 1.67 . However lower values can be found in other stable calcium phosphates such as brushite $(\mathrm{Ca} / \mathrm{P}=1)$, which for certain conditions can precede the formation of apatite. The XRD pattern of the composite for several immersion times in SBF (Fig. 3) gave no indications of crystalline calcium phosphate.

The preliminary results obtained so far indicate that PMMA-co-EHA composites filled with a $\mathrm{SiO}_{2}$ free glass can induce the formation of calcium phosphate precipitates on their surface after immersion in a synthetic physiological fluid. These calcium phosphate precipitates exhibit a $\mathrm{Ca} / \mathrm{P}$ atomic ratio around 1, corresponding to brushite, a typical precursor of apatite formation, as required for a bioactive behaviour.

References:

[1] H. Takadama, H.-M. Kim, T. Kokubo, T. Nakamura, J. Am. Ceram. Soc. 85 (2002) 1933.

[2] T. Kokubo, Acta Metallurgica Inc. 46 (1998) 2519. 

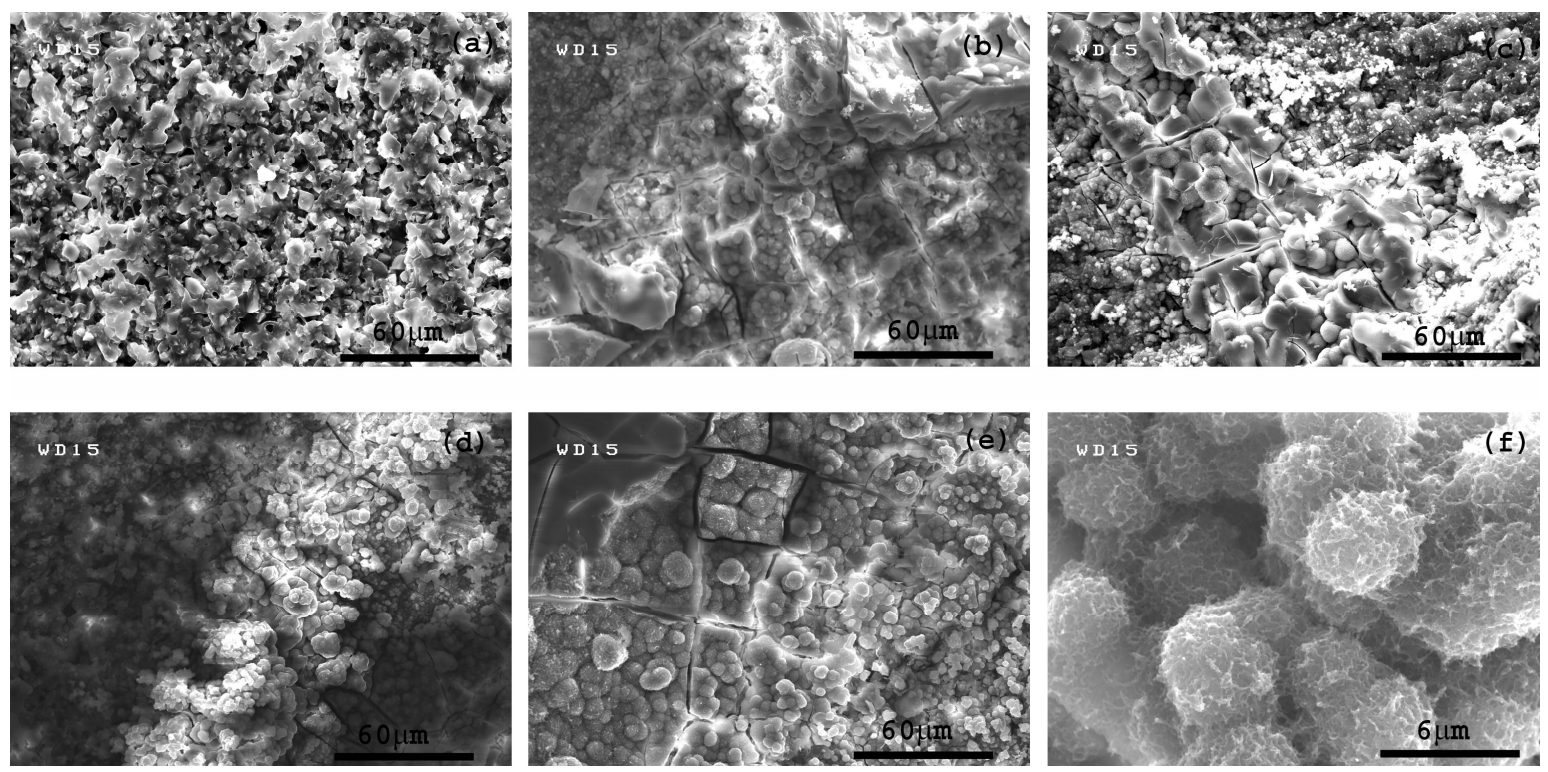

Fig. 1. SEM images of the composite surface (a) before SBF, (b) after 3 days of immersion, (c) 7 days, (d) 14 days, (e) and (f) 21 days.
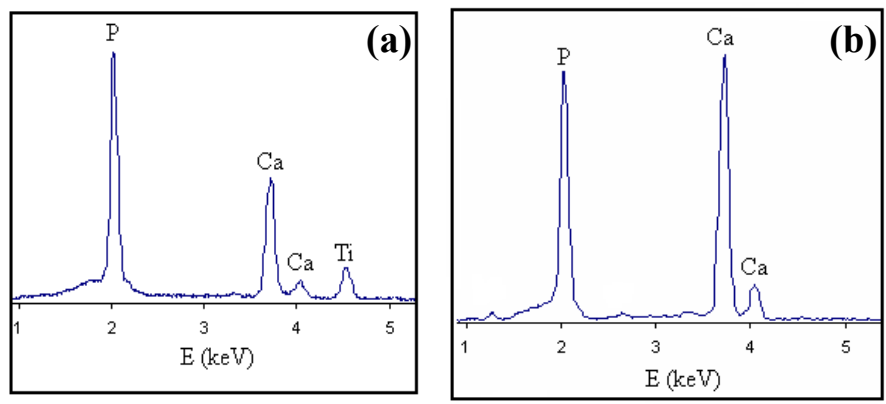

Fig. 2. EDS analysis of the composite surface (a) before and (b) after soaking in SBF for 3 days.

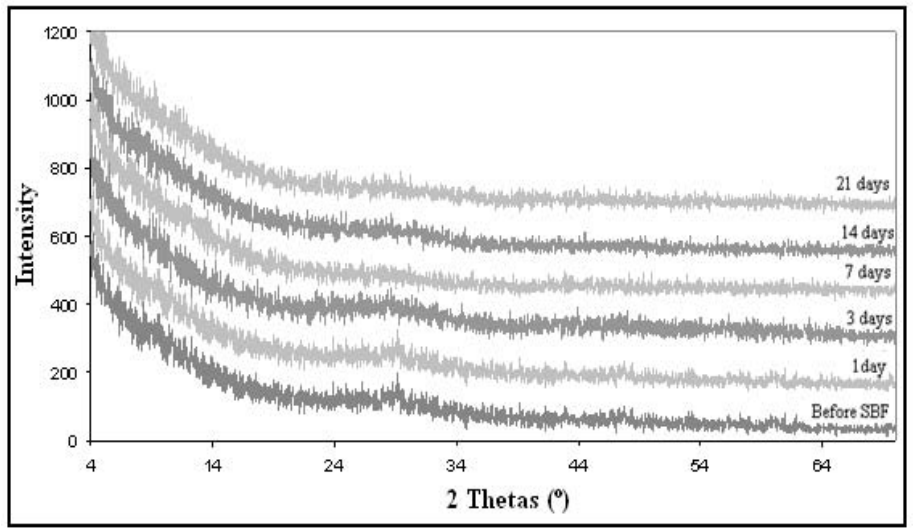

Fig. 3. XRD pattern of composite before and after different periods of time in SBF 